\title{
A social work study on quality and quantity of physical education teachers in elementary schools
}

\author{
Allahyar Arabmomeni ${ }^{\mathbf{a}^{*}}$ and khodayar Momeni ${ }^{\mathbf{b}}$
}

${ }^{a}$ Department of Human Science of Islamic Azad University Khomeinishahr Branch, Isfahan, Iran ${ }^{b}$ Department of Human Science of Islamic Azad University Dolat Abad Branch, Isfahan, Iran

C H R O N I C L E

Article history:

Received October 25, 2012

Received in revised format

8 January 2013

Accepted 20 January 2013

Available online

February 12013

Keywords:

Physical education

Elementary schools

Educational programs

\section{A B S T R A C T}

This paper presents an empirical survey on the performance of physical education programs among elementary schoolchildren in city of Esfahan, Iran over the period 2010-2011. The study selects 18 non-for-profit and 34 governmental schools as samples and performs an empirical investigation on various personal characteristics of teachers in two different schools. The study investigates whether there is any difference between teachers' age, education, area of education, having any coach, referee certificate and in-service courses in two types of non-for-profit and governmental schools. The results of our investigation show that physical education has a somewhat better quality in non-for-profit educational system compared with governmental ones but this difference is not statistically significance $(\mathrm{P}<0.05)$ in most cases except the cases of age and educational background.

\section{Introduction}

Physical education (PE) plays an important role on health and academic performance of schoolchildren (Sallis \& McKenzie, 1991; McKenzie et al., 1996; Trudeau et al., 1999; Burgeson et al., 2001). Trudeau and Shephard (2008) studied the relationship between academic achievement and involvement in PE, school physical activity (PA) and sport programs and reported that school PA could be considered as a consistent component of PA to provide some guidelines for children and adolescents without impairing academic achievement, even if curricular time for so-called academic subjects is curtailed. Nahas et al. (2003) Reviewed different factors, which influence high school and college students' physical activity adoption and/or maintenance. Relevant determinants of PA include self-efficacy, intentions, perceived barriers, enjoyment, stages of change, and social support. They also recommended that behavior modifications could increase PA involvement include by developing self-regulatory skills and increasing social support. 
Ntoumanis (2005) performed an investigation to study on participation in optional school physical education using a self-determination theory framework. He studied whether contextual and personal motivational variables, taken from self-determination theory, could forecast student cognitive and affective experiences in school PE, as well as participation in optional PE in the following school year using a structural equation modeling analysis. The study used a sample of 302 British adolescents and demonstrated that need support provided by the PE teachers was associated with student need satisfaction, which in turn forecasted self-determined motivation. The latter predicted directly different motivational indices and indirectly future participation in optional PE.

According to Lee et al. (2006), to enhance PE and PA in schools, a comprehensive method at the state, district, school, and classroom levels is essential. Policies, practices, and comprehensive staff development at the state and district levels could enable schools to improve opportunities for students to become physically active adults. There are other researchers who either directly or indirectly emphasis on these issues (Subramaniam \& Silverman, 2007; Chedzoy \& Burden, 2009; Rasberry et al., 2011).

When there is no physical activities people may experience obesity (Fernandes \& Sturm, 2010), which harms people's health. van Beurden et al. (2003) explained that PE lessons could be an ideal setting to improve child fundamental movement skills (FMSs) and improve PA for optimal health. Hastie and Saunders (1991) studied the accountability in secondary school PE by examining the interrelationships among the variables associated with accountability, namely, active instruction, monitoring, and the rewards system operating in classes. They examined their model using Linear Structural Relations and reported that the accountability factors of monitoring directly impacted involvement while active instruction and the rewards system impacted involvement indirectly through the students' valuing of the teacher. van Beurden et al. (2003) investigated whether it is possible to skill and to activate children through primary school PE lessons. They provided some evidences for the reliability and validity of measures extracted from some tripartite efficacy instruments.

Rengasamy (2012) executed a physical fitness intervention program within a PE class on some selected health-related fitness among Malaysian secondary school girls and reported that a ten-week physical fitness program within a physical education class could be effective in enhancing cardiovascular endurance and flexibility. Theodosiou and Papaioannou (2006) studied motivational climate, achievement objectives and metacognitive activity in PE and exercise involvement in out-ofschool settings. They underscored the importance of task orientation and mastery climate for the development of metacognition in $\mathrm{PE}$ and underlined the necessary of research on the causal relationship between metacognition and sport involvement.

Cox et al. (2008) explained that the efficacy of school-based physical activity interventions, within and outside of school, was related to the degree of support for students' self-determined motivation. Katartzi and Vlachopoulos (2011) studied motivating children with developmental coordination disorder in school PE. Dudley et al. (2012) detected the levels of PA, lesson context and teacher interaction students receive during PE programs in secondary schools in New South Wales, Australia. They suggested that levels of skill instruction and practice were well below international. Aktop and Karahan (2012) studied teacher's PE self-reported view on different teaching methods and Turkish physical education curriculum and studied the gender differences in selecting the teaching methods and reported that there was an incongruity between teacher's PE views, preferences and Turkish physical education Curriculum recommending on teaching methods for PE classes

This paper investigates PE components among schoolchildren who attend elementary schools in city of Esfahan, Iran over the period 2010-2011, chooses 52 schools as sample, where 18 are non-forprofit and 34 are governmental schools. In this paper, we study PE among schoolchildren who were attending elementary schools in city of Esfahan, Iran over the period 2010-2011. We first present the 
proposed study in section 2, while details of the findings are presented in section 3 and concluding remarks are demonstrated in the last.

\section{The proposed study}

In our study, the sample size is calculated as follows,

$$
n=\frac{N \times z_{\alpha / 2}^{2} \times p \times q}{\varepsilon^{2} \times(N-1)+z_{\alpha / 2}^{2} \times p \times q},
$$

where $N$ is the population size, $p=1-q$ represents the yes/no categories, $z_{\alpha / 2}$ is CDF of normal distribution and finally $\varepsilon$ is the error term. Since we have $p=0.5, z_{\alpha / 2}=1.96$ and $N=557$, the number of sample size is calculated as $n=52$. The society has been divided into five regions and Table 1 demonstrates details of our sample size.

\section{Table 1}

Details of survey population

\begin{tabular}{cccccc}
\hline & \multicolumn{2}{c}{ Population } & \multicolumn{3}{c}{ Sample size } \\
Region & Governmental & Non-for-profit & Society & Governmental & Non for profit \\
\hline 1 & 50 & 12 & 62 & 4 & 2 \\
2 & 48 & 19 & 67 & 4 & 2 \\
3 & 102 & 29 & 111 & 8 & 4 \\
4 & 103 & 36 & 139 & 8 & 4 \\
5 & 116 & 42 & 158 & 10 & 6 \\
\hline Total & 419 & 138 & 557 & 34 & 18 \\
\hline
\end{tabular}

The proposed study uses a standard questionnaire consists of 26 questions covering PE characteristics about what participants believe about the quality and quantity of different courses. The questionnaire was arranged in in Likert scale from one to five, where one represents a weak and five represents strong point. Table 2 demonstrates the participants age frequencies in various categories.

Table 2

Diversity of the participants in terms of their age

\begin{tabular}{cccccccccc}
\hline & \multicolumn{2}{c}{ Less than 25} & \multicolumn{2}{c}{$25-35$} & \multicolumn{2}{c}{$36-45$} & \multicolumn{2}{c}{ More than 45} \\
\cline { 2 - 9 } Region & Freq. & $\%$ & Freq. & $\%$ & Freq. & $\%$ & Freq. & $\%$ \\
\hline 1 & 1 & 16.67 & 2 & 33.33 & 2 & 33.33 & 1 & 16.67 \\
2 & 0 & 0 & 1 & 16.67 & 4 & 66.67 & 0 & 16.67 \\
3 & 1 & 8.33 & 5 & 41.67 & 4 & 33.33 & 1 & 16.67 \\
4 & 1 & 8.33 & 2 & 16.67 & 6 & 50 & 1 & 25 & 1 \\
5 & 1 & 6.25 & 7 & 43.75 & 3 & 18.75 & 1.25 \\
\hline
\end{tabular}

According to Table 2, most PE teachers aged between 25 and 45 years, PE teachers who attend schools in region 5 seem to be in higher level of education. Fig. 1 shows educational backgrounds of the participants.

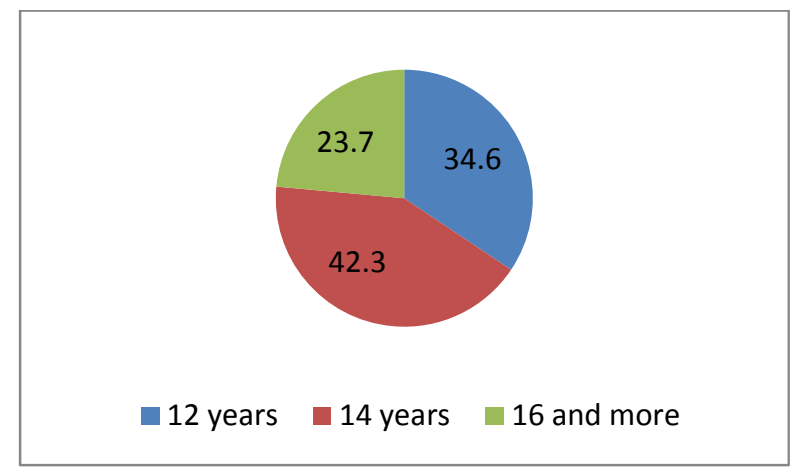

Fig. 1. (a) Schoolchildren for boys

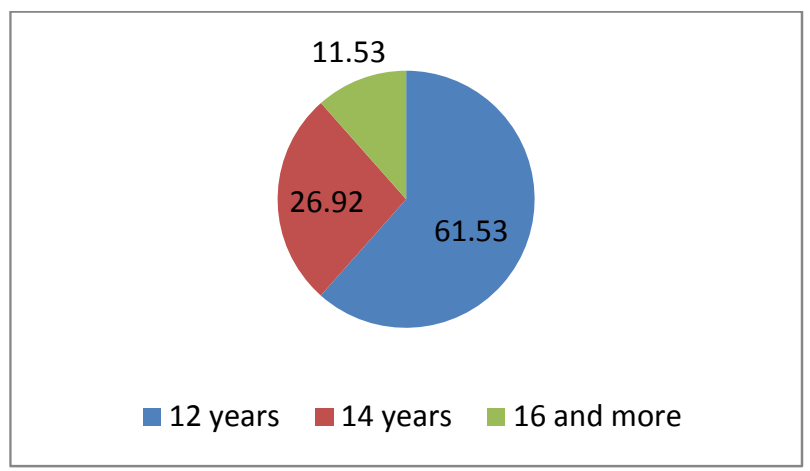

Fig. 1. (b) Schoolchildren for girls

Fig. 1. PE teachers' years of educational backgrounds 
As we can observe from Fig. 1, most PE teachers who teach female students only managed to finish high schools while PE teachers who train male students maintain a two-year college degree. Therefore, in terms of descriptive statistics, we can find some differences between female and male PE teachers on their educational backgrounds. Note that, in our survey, only $11.7 \%$ of PE teachers who worked for governmental schools hold PE related degrees while this ratio was $55.55 \%$ in nonfor-profit organizations. Fig. 2 shows details of our teachers' characteristics in terms of PE related educational backgrounds.

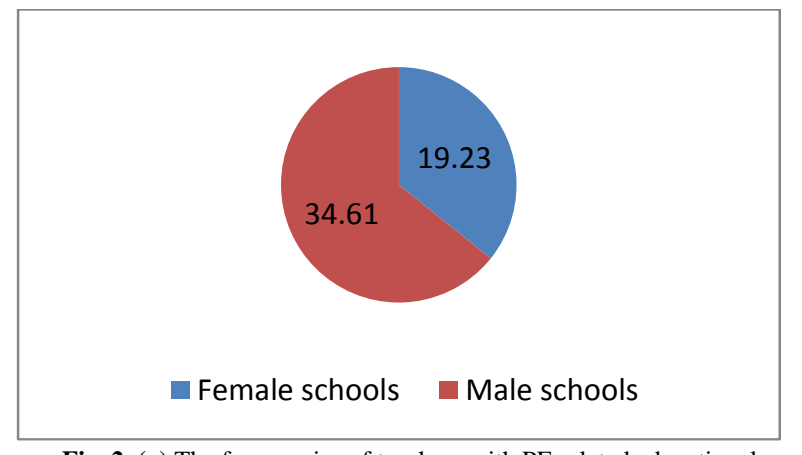

Fig. 2. (a) The frequencies of teachers with PE related educational backgrounds

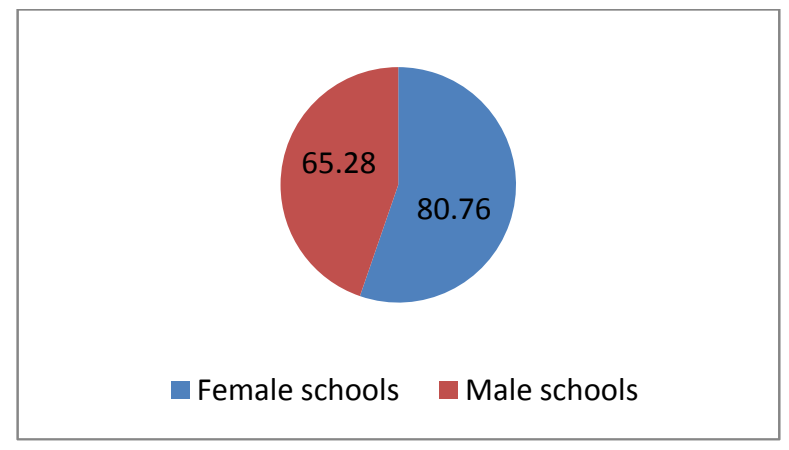

Fig. 2. (b) The frequencies of teachers with not PE related educational backgrounds

Fig. 2. The frequencies of teachers in terms of related/unrelated PE educational backgrounds

Based on the results of Fig. 2, we can observe that teachers with PE related educational background are fewer than not PE related educational background. Another interesting thing to investigate on the number of in-service courses PE teachers has spent. Fig. 3 shows details of our survey.

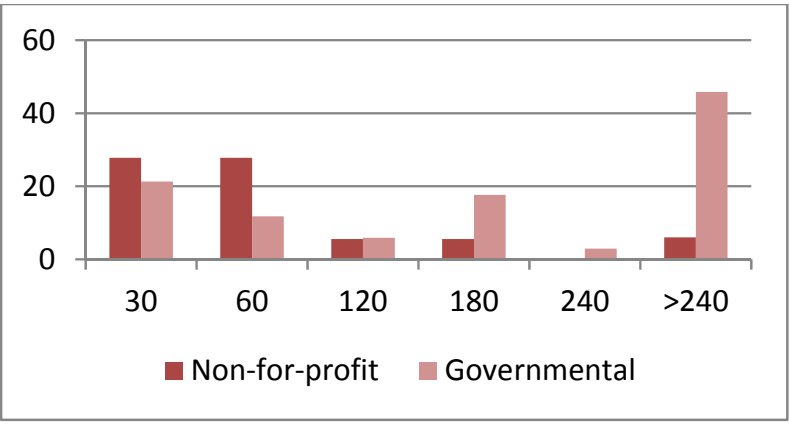

Fig. 2. (a) The frequencies of the number of in-service course in terms of non-for-profit and governmental schools

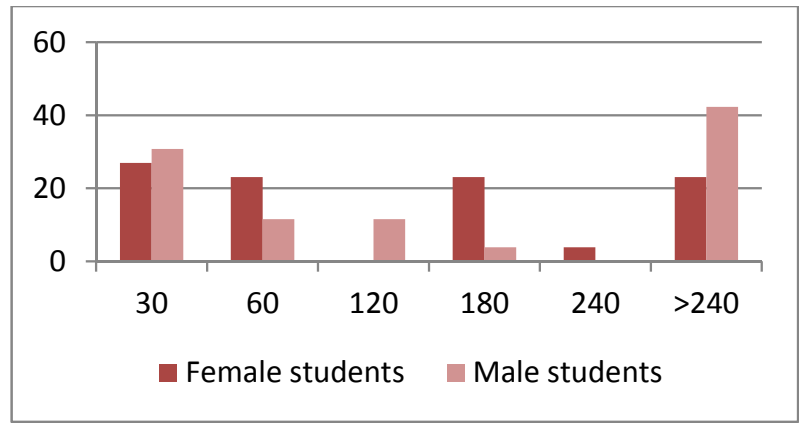

Fig. 2. (b) The frequencies of the number of in-service course in terms of female and male type schools

Fig. 2. The frequencies of the number of taken in-service courses PE teachers

Fig. 2 shows the frequencies of the number of hours teachers have spent on upgrading their skills using in-service short course programs. In both non-for-profit and governmental schools, some governmental teachers spend over 240 hours on learning new skills while fewer non-for-profit teachers this amount of time to learn. Next, we perform some statistical test to verify whether there is any difference between different items investigated in our survey or not.

\section{The results}

The proposed study of this paper uses t-student and Chi-Square tests to verify whether there is any difference between the components of this survey or not.

\subsection{Human resource in governmental non-for-profit organizations}

We first examine whether there is any difference between various personal characteristics of the PE teachers in governmental and non-for-profit organizations. Table 3 demonstrates the results of our survey. 
Table 3

The results of t-student on governmental and non-for-profit PE teachers

\begin{tabular}{|c|c|c|c|c|c|c|c|}
\hline Item & Variable & PE teacher & Number & Mean & $\mathrm{t}$-value & $\mathrm{df}$ & P-value \\
\hline \multirow[b]{2}{*}{1} & \multirow{2}{*}{ Age } & Governmental & 35 & 3.2 & 2.3 & 50 & 0.062 \\
\hline & & Non-for-profit & 17 & 2.5 & & & \\
\hline \multirow[b]{2}{*}{2} & \multirow{2}{*}{ Educational background } & Governmental & 35 & 1.6 & 1.7 & 50 & 0.098 \\
\hline & & Non-for-profit & 17 & 1.9 & & & \\
\hline \multirow[b]{2}{*}{3} & \multirow{2}{*}{ Job experience } & Governmental & 35 & 3.9 & 1.25 & 50 & 0.0216 \\
\hline & & Non-for-profit & 17 & 3.3 & & & \\
\hline \multirow[b]{2}{*}{4} & \multirow{2}{*}{ Coach certificate } & Governmental & 35 & 1.4 & 0.4 & 50 & 0.70 \\
\hline & & Non-for-profit & 17 & 1.5 & & & \\
\hline \multirow[b]{2}{*}{5} & \multirow[b]{2}{*}{ Referee certificate } & Governmental & 35 & 1 & 0.14 & 50 & 0.9 \\
\hline & & Non-for-profit & 17 & 1 & & & \\
\hline \multirow[b]{2}{*}{6} & \multirow{2}{*}{ In-service courses } & Governmental & 35 & 3.4 & 0.21 & 50 & 0.8 \\
\hline & & Non-for-profit & 17 & 3.3 & & & \\
\hline
\end{tabular}

The results of t-student values indicate that the first items, age, educational background and job experience, are statistically significance. Table 4 shows the results of examining various personal characteristics on different groups of schools in terms of gender.

\subsection{Human resource among female and male type schools}

As we can observe from the results of Table 4, only age, educational background and job experience are statistically different between female and male type schools but the other three items, coach certificate, referee certificate as well as in-service courses are not statistically different between two types of schools.

\section{Table 4}

The results of t-student on female and male type students' PE teachers

\begin{tabular}{|c|c|c|c|c|c|c|c|}
\hline Item & Variable & PE teacher & Number & Mean & $\mathrm{t}$-value & $\mathrm{df}$ & P-value \\
\hline \multirow[b]{2}{*}{1} & \multirow{2}{*}{ Age } & Male & 26 & 3.19 & 1.7 & 50 & 0.009 \\
\hline & & Female & 26 & 2.8 & & & \\
\hline \multirow[b]{2}{*}{2} & \multirow{2}{*}{ Educational background } & Male & 26 & 1.9 & 1.9 & 50 & 0.007 \\
\hline & & Female & 26 & 1.5 & & & \\
\hline \multirow[b]{2}{*}{3} & \multirow{2}{*}{ Job experience } & Male & 26 & 4.19 & 2.30 & 50 & 0.003 \\
\hline & & Female & 26 & 3.3 & & & \\
\hline \multirow[b]{2}{*}{4} & \multirow[b]{2}{*}{ Coach certificate } & Male & 26 & 1.5 & 0.21 & 50 & 0.8 \\
\hline & & Female & 26 & 1.4 & & & \\
\hline \multirow[b]{2}{*}{5} & \multirow[b]{2}{*}{ Referee certificate } & Male & 26 & 1.4 & 1.6 & 50 & 0.11 \\
\hline & & Female & 26 & 0.80 & & & \\
\hline \multirow[b]{2}{*}{6} & \multirow{2}{*}{ In-service courses } & Male & 26 & 3.6 & 0.7 & 50 & 0.5 \\
\hline & & Female & 26 & 3.2 & & & \\
\hline
\end{tabular}

\section{Conclusion}

In this paper, we have presented a study the impact of three personal characteristics and three skill based certificates between PE teachers who worked for governmental or non-for-profit schoolchildren. The results have indicated that teachers who work for non-for-profit schools have different personal characteristics compared with those who work for governmental schools.

\section{References}

Aktop, A., \& Karahan, N. (2012). Physical education teacher's views of effective teaching methods in physical education. Procedia - Social and Behavioral Sciences, 46, 1910-1913. 
Burgeson, C. R., Wechsler, H., Brener, N. D., Young, J. C., \& Spain, C. G. (2001). Physical education and activity: results from the School Health Policies and Programs Study 2000. Journal of School Health, 71(7), 279-293.

Chedzoy, S., \& Burden, R. (2009). Primary school children's reflections on Physical Education lessons: An attributional analysis and possible implications for teacher action. Thinking Skills and Creativity, 4(3), 185-193.

Cox, A.E., Smith, A.L., \& Williams, L. (2008). Change in physical education motivation and physical activity behavior during middle school. Journal of Adolescent Health, 43(5), 506-513.

Dudley, D.A., Okely, A.D., Cotton, W.G., Pearson, P., \& Caputi, P. (2012). Physical activity levels and movement skill instruction in secondary school physical education. Journal of Science and Medicine in Sport, 15(3), 231-237

Fernandes, M., \& Sturm, R. (2010). Facility provision in elementary schools: Correlates with physical education, recess, and obesity. Preventive Medicine, 50, S30-S35.

Hastie, P.A., \& Saunders, J.E. (1991). Accountability in secondary school physical education. Teaching and Teacher Education, 7(4), 373-382.

Katartzi, E.S., \& Vlachopoulos, S.P. (2011). Motivating children with developmental coordination disorder in school physical education: The self-determination theory approach. Research in Developmental Disabilities, 32(6), 2674-2682

Lee, S. M., Burgeson, C. R., Fulton, J. E., \& Spain, C. G. (2007). Physical education and physical activity: results from the School Health Policies and Programs Study 2006. Journal of School Health, 77(8), 435-463.

McKenzie, T. L., Nader, P. R., Strikmiller, P. K., \& Yang, M. (1996). School physical education: effect of the Child and Adolescent Trial for Cardiovascular Health. Preventive Medicine: An International Journal Devoted to Practice and Theory.

Nahas, M. V., Goldfine, B., \& Collins, M. A. (2003). Determinants of Physical Activity in Adolescents and Young Adults: The Basis for High School and College Physical Education To Promote Active Lifestyles. Physical Educator,60(1), 42-56.

Ntoumanis, N. (2005). A prospective study of participation in optional school physical education using a self-determination theory framework. Journal of educational psychology, 97(3), 444.

Rasberry, C.N., Lee, S.M., Robin, L., Laris, B.A., Russell, L.A., Coyle, K.G., \& Nihiser, A.J. (2011). The association between school-based physical activity, including physical education, and academic performance: A systematic review of the literature Review article. Preventive Medicine, 52(1), S10-S20.

Rengasamy, S. (2012). A physical fitness intervention program within a physical education class on selected health-related fitness among secondary school students. Procedia - Social and Behavioral Sciences, 55, 1104-1112.

Sallis, J. F., \& McKenzie, T. L. (1991). Physical education's role in public health. Research Quarterly for Exercise and Sport, 62(2), 124.

Subramaniam, P.R., \& Silverman, S. (2007). Middle school students’ attitudes toward physical education. Teaching and Teacher Education, 23(5), 602-611.

Theodosiou, A., \& Papaioannou, A. (2006). Motivational climate, achievement goals and metacognitive activity in physical education and exercise involvement in out-of-school settings. Psychology of Sport and Exercise, 7(4), 361-379

Trudeau, F. R. A. N. Ç. O. I. S., Laurencelle, L. O. U. I. S., Tremblay, J. A. N. I. E., Rajic, M. I. R. J. A. N. A., \& Shephard, R. J. (1999). Daily primary school physical education: effects on physical activity during adult life. Medicine and Science in Sports and Exercise, 31(1), 111.

Trudeau, F., \& Shephard, R. J. (2008). Physical education, school physical activity, school sports and academic performance. International Journal of Behavioral Nutrition and Physical Activity, 5(1), 10.

van Beurden, E., Barnett, L.M ., Zask, A., Dietrich, U.C., Brooks, L.O., \& Beard, J. (2003). Can we skill and activate children through primary school physical education lessons? "move it groove it”-a collaborative health promotion intervention. Preventive Medicine, 36(4), 493-501. 